\title{
RESEARCH WAYS TO INCREASE THE ENERGY EFFICIENCY OF GROUND HEAT EXCHANGERS BY MEANS OF MATHEMATICAL SIMULATION
}

\begin{abstract}
Oleksiy KOVIAZIN, Zaporizhzhia National University, st. Zhukovsky, 66, Zaporizhzhia 69600, Ukraine, kvznas@ gmail.com Andriy POZHUYEV, Zaporizhzhia National University, st. Zhukovsky, 66, Zaporizhzhia 69600, Ukraine, scorpio6828@gmail.com Olena MIKHAILUTSA, Zaporizhzhia National University, st. Zhukovsky, 66, Zaporizhzhia 69600, Ukraine, elenamikhaylutsa7@gmail.com (corresponding author)

Nataliia POLIAKOVA, Zaporizhzhia National University, st. Zhukovsky, 66, Zaporizhzhia 69600, Ukraine, natalypol@yahoo.com Tetiana MELIKHOVA, Zaporizhzhia National University, st. Zhukovsky, 66, Zaporizhzhia 69600, Ukraine, tanya_zp_zgia@ukr.net

The scientific and methodological basis for increasing the efficiency of geothermal ventilation, making it possible to use thermal energy of the Earth's surface layers for cooling (heating) an incoming air stream are created. Mathematical modeling is performed based on the equations of hydrodynamics, heat transfer and thermal conductivity, along with a computational experiment carried out using the finite volume method. A mathematical model of the process of heat exchange between the flow of air in a heat exchanger and a soil mass is developed. This model describes a relationship between efficiency indicators of the horizontal ground heat exchanger and its performance parameters, and also natural climatic conditions. The determination of thermal fields in incoming cooled air and a soil mass at various depth locations of the horizontal ground heat exchanger is performed. The relationship between thermal efficiency and operation time of the horizontal heat exchanger, located at different depths, is proved. The energy comparison of a horizontal ground heat exchanger, located at different depths, with a vertical one, is made. he depth of the horizontal heat exchanger has been established, for which the loss of thermal energy in comparison with the vertical is insignificant (less than 7.5\%). The operating time was determined, starting from which there are practically no differences in the level of thermal energy for all the studied models $\left(>10^{7} \mathrm{~s}\right)$. The developed mathematical model allows to predict the energy efficiency indicators of a horizontal ground heat exchanger on the basis of its performance parameters and natural climatic conditions, that makes possible determining the economically optimal depth of the heat exchanger location under specific conditions.
\end{abstract}

Keywords: computational experiment, Earth's surface layers, horizontal ground heat exchanger, incoming air, mathematical model, thermal energy.

\section{INTRODUCTION}

One of the global problems is the rational use of fuel and energy resources. It is believed that a promising way to solve this problem is the appliance of new energy-saving technologies that use alternative renewable energy sources. The utilization of low-grade ground heat as the direction of alternative energy has been actively developed abroad (Wołoszyn, 2017; Benli, 2013; Chiasson, 2010; Soni, 2015).

Providing an optimal microclimate for livestock premises requires significant energy and money expenses. Without observance of the optimal microclimate, the influence of which consists of the combined effects of temperature, humidity, gas composition of air and air pollution, it is impossible to get cheap and high-quality products in a short period. Numerous studies have shown that farms where animals are kept in premises with air, in which the concentration of ammonia, hydrogen sulfide, carbon dioxide is above the norm, will suffer significant losses resulting from animal productivity decrease, increased animal mortality, as well as overconsumption of feed (Bugayevsky, 2010).

Reducing the expenses of energy for optimal microclimate is one of the ways to improve the efficiency of the livestock industry and can become possible due to the use of alternative energy sources, in particular geothermal energy.

It is known that ground is an inexhaustible source of thermal energy, the geothermal heat from which can only be removed using heat pumps. Vertical ground heat exchangers work effectively in almost all types of geological terrain, with the exception of ground with low thermal conductivity, for example, dry sand or dry gravel. Systems with vertical ground heat exchangers are very widespread, in particular in the field of animal husbandry. They allow cooling (heating) of the supply air for livestock premises (Koviazin, 2011).

The principle of geothermal ventilation with the use of ground heat exchangers (Fig. 1) is that air with temperature $T_{l}$ is supplied to the inlet of the ground heat exchanger and releases (takes) the heat from the soil, resulting in air being cooled (heated), acquiring the temperature $T_{2}$, and is supplied in the livestock premises. The well is filled with grouting mortar conductivity, which improves heat transfer between the casing pipe and the ground. The casing pipe is made of a material with high thermal conductivity, for example, of steel. In this case, a heat flow $d Q / d t$ arises between the inner 
surface of the casing pipe of a heat exchanger, which has an internal diameter $D$, and the soil massif, the value of which determines the energy extraction of the heat exchanger from the soil massif. To improve the efficiency of geothermal ventilation, it is necessary to substantiate the parameters of a ground heat exchanger.

\section{ANALYSIS OF RECENT RESEARCH AND PUBLICATIONS}

The experimental comparison of a horizontal ground heat exchanger with a vertical one is given in work [Benli, 2013]. The author determined the COP (Coefficient of Performance) transformation ranges for different spatial

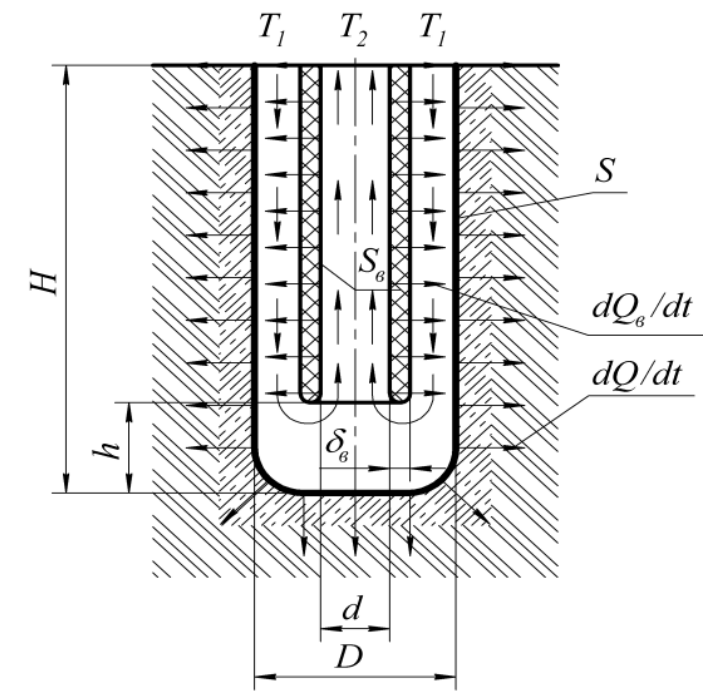

Figure 1. Longitudinal section of vertical ground heat exchanger orientations of the heat exchanger and concluded that the use of a heat pump with a horizontal ground heat exchanger, although energetically and slightly inferior to the vertical, but for the climatic conditions in which the experiment was conducted is quite justified. However, the results of this work are reliable only for the conditions of the experiment.

In work (Mironov, 2016) a heat transfer model of the horizontal heat exchanger is developed. The soil massif temperature is assumed as non-changing through the whole depth and has some average values at the initial time moment; the temperature of the pipe surface is uniform and constant over the time. That is, a cylinder of finite size horizontally located in half-space is considered. But in real conditions, the soil temperature in depth is irregular and is constantly changing, depending on the daily and seasonal fluctuations of temperature on the top of the soil, as well as on the actions of the internal warmth of the Earth. And, since the horizontal ground heat exchanger is close to the ground surface, seasonal fluctuations in soil temperature, which are particularly strong in these layers, must be taken into account for reliable results. The natural distribution of the soil temperature (that is, without any thermal effect of heat exchangers on a soil massif) in depth can be determined, for example, by the algorithm that is developed in the article (Shevchenko, 2017). The surface temperature of the pipe is also irregular and constantly changes over time due to the depletion of the energy potential of the soil massif. Therefore, the developed model can only be used for preliminary estimation of thermal power of a horizontal ground heat exchanger.

In the article (Larwa, 2016), the heat transfer of three parallel-installed ground heat exchangers is considered. It is also assumed that the temperature of the pipe surface is steady and constant over time. When modeling, the heat conductivity of the soil depended on depth, but not as a function, but for some reason discrete. The authors oversimplify the process they are investigating up to the one-dimensional heat transfer equation. The obtained dependences help to better understand the distribution of heat in the depth at the operation of horizontal ground heat exchangers, but nevertheless, it is still too simplistic.

In (Chiasson, 2010), the author simulates the heat transfer of a system consisting of six horizontal heat exchangers in a two-dimensional cross-section with time-varying boundary conditions on the surface of the soil and on the internal heat transfer surfaces. The calculated area is a rectangle with adiabatic walls on the left and right boundaries. On the upper boundary, which is the soil surface, the natural and climatic conditions are modeled as a Neumann condition. At the lower boundary, which is located at a depth of $10 \mathrm{~m}$, a constant temperature is set. According to our research [Shevchenko, 2017], even seasonal temperature fluctuations may reach greater depths, and the thermal effects of ground heat exchangers system can be extended to greater depths, especially with intensive use of soil energy potential. Therefore, it would be desirable to set the lower boundary at a depth of at least $20 \mathrm{~m}$. In addition, the two-dimensional model cannot adequately describe the heat transfer in the system of ground heat exchangers located in three-dimensional space.

The article (Wołoszyn, 2017) theoretically studies the energy efficiency of horizontal ground heat exchangers system with simultaneous use of the sub-surface humidification system, through which it is possible to automatically control the soil humidity (and hence its temperature conductivity), which is in close proximity to the heat exchangers. The authors note that conducting a full-scale experiment is very expensive, while three-dimensional numerical simulation takes a lot of time, so the modified quasi-3D heat transfer model (Wołoszyn, 2013; Wołoszyn, 2016) is used to greatly simplify the investigation process.

In (Sivasakthivel, 2014), the Taguchi method is used to optimize the parameters of a vertical ground heat exchanger. In work (Ji, 2017) an improved 3D model of linear sewage is developed, which allows to determine the temperature of the working fluid at the inlet / outlet of a heat exchanger. In (Soni, 2015) a detailed review of ground heat exchangers is carried out, with the definition of their advantages and disadvantages. In the source (Atam, 2016), an overview of the current state of ground heat exchangers simulation is carried out.

In articles (Shevchenko, 2017; Koviazin, 2013; Koviazin, 2017), a mathematical model of heat exchange process between the air that moves in a vertical heat exchanger and a soil massif, which binds together the energy indices of the ground heat exchanger with its parameters, as well as the natural and climatic conditions, is developed. The natural convection of air in closed channels for small temperature gradients is considered in the work (Cheilytko, 2017). The author takes into account flow turbulence by means of correction coefficients, but does not use modern turbulence models. 
Based on the present analysis, it can be concluded that mathematical modeling with computational experiments is an important area for investigation of vertical or horizontal ground heat exchangers, since conducting experimental research on real objects requires large investments.

\section{MATERIALS AND METHODS}

The calculation scheme of the horizontal ground heat exchanger is depicted in Fig. 2.

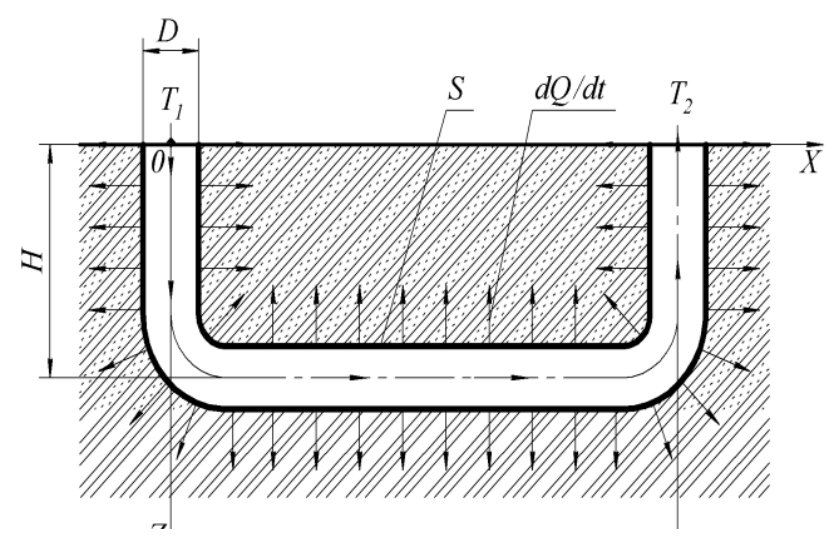

Figure 2. Longitudinal section of the horizontal ground heat exchanger

We introduce the rectangular system of coordinates OXYZ so that its beginning can be found on the axis of the input vertical part of the ground heat exchanger, the axis OX is directed along the horizon and parallel to the axis of the horizontal section of the heat exchanger, the axis OY is directed perpendicular to the plane of the figure and the $\mathrm{OZ}$ axis is directed vertically downwards.

The area occupied by the input vertical section of the ground heat exchanger

$M_{\text {in }}=\left\{(x, y, z) \mid x^{2}+y^{2} \leq D^{2} / 4, z \geq 0, z+x \leq H+D / 2\right\}$, (1)

where $H$ - the depth of the location of the horizontal ground heat exchanger, for the research we take $H=1 ; 2$ and $3 \mathrm{~m}$.

The area occupied by the horizontal section of the ground heat exchanger

$$
\begin{aligned}
M_{h o r}= & \left\{(x, y, z) \mid y^{2}+(z-H)^{2} \leq D^{2} / 4,\right. \\
& z+x>H+D / 2, z-x>H+D / 2-L\},
\end{aligned}
$$

where $L$ - the length of the horizontal section of the ground heat exchanger, we take $L=30 \mathrm{~m}$ for research.

The area occupied by the output vertical section of the ground heat exchanger

$$
\begin{aligned}
M_{\text {out }}= & \left\{(x, y, z) \mid(x-L)^{2}+y^{2} \leq D^{2} / 4,\right. \\
& z \geq 0, z-x \leq H+D / 2-L\} .
\end{aligned}
$$

Then the area that occupies the air

$$
M_{\text {air }}=M_{\text {in }} \cup M_{\text {hor }} \cup M_{\text {out }},
$$

and the area occupied by the soil

$$
M_{s}=\left\{(x, y, z) \mid(z \geq 0) \backslash M_{\text {air }}\right\} .
$$

We accept the following assumptions:

- the soil is homogeneous and isotropic, and its thermophysical properties remain constant with temperature change;

- the thermal contact of the casing with the surrounding soil is perfect;

- do not consider the presence of a casing of a ground heat exchanger, that is, we accept the thickness of the casing pipe $\delta=0$ [Koviazin, 2013];

- due to the slight change of the pressure in the air flow during its movement in the ground heat exchanger, air is considered as a incompressible liquid. exchanger

The heat flowing through the heat transfer surface $S$ at a given time $t$ of the functioning of the ground heat

$$
\frac{d Q}{d t}=-\lambda_{s} \int_{S} \frac{\partial T_{s}}{\partial n} d S,
$$

where $T_{s}(x, y, z, t)$ - temperature at the soil point, which has coordinates $(x, y, z)$ at time $t,{ }^{\circ} \mathrm{C}$.

The equation of continuity, which reflects the fact of absence in the field, which occupied by the air $M_{\text {air }}$, of emptiness and discontinuities, in the adopted rectangular coordinate system, has the form

$$
\frac{\partial u}{\partial x}+\frac{\partial v}{\partial y}+\frac{\partial w}{\partial z}=0,(x, y, z) \in M_{a i r}
$$

where $u, v, w$-components of velocity in directions $x, y, z$.

The motion of air in this case is described by the Navier-Stokes equations, which take the form for rectangular coordinates

$$
\begin{aligned}
\rho \frac{D u}{\partial t} & =-\frac{\partial p}{\partial x}+\mu \nabla^{2} u, \quad \rho \frac{D v}{\partial t}=-\frac{\partial p}{\partial y}+\mu \nabla^{2} v, \\
\rho \frac{D w}{\partial t} & =-\frac{\partial p}{\partial z}+\mu \nabla^{2} w, \quad(x, y, z) \in M_{\text {air }} .
\end{aligned}
$$

Substantial derivatives that are included in the previous equations are expressed by dependencies 


$$
\begin{aligned}
& \frac{D u}{\partial t}=\frac{\partial u}{\partial t}+u \frac{\partial u}{\partial x}+v \frac{\partial u}{\partial y}+w \frac{\partial u}{\partial z} \\
& \frac{D v}{\partial t}=\frac{\partial v}{\partial t}+u \frac{\partial v}{\partial x}+v \frac{\partial v}{\partial y}+w \frac{\partial v}{\partial z} \\
& \frac{D w}{\partial t}=\frac{\partial w}{\partial t}+u \frac{\partial w}{\partial x}+v \frac{\partial w}{\partial y}+w \frac{\partial w}{\partial z}
\end{aligned}
$$

The Laplace operator in the rectangular coordinate system has the form

$$
\nabla^{2}=\left(\frac{\partial^{2}}{\partial x^{2}}+\frac{\partial^{2}}{\partial y^{2}}+\frac{\partial^{2}}{\partial z^{2}}\right)
$$

The temperature field in the moving air flow is described by the energy equation

$$
\frac{D T_{\text {air }}}{\partial t}=a_{\text {air }} \nabla^{2} T_{\text {air }},(x, y, z) \in M_{\text {air }},
$$

where $T_{\text {air }}(x, y, z, t)$ - temperature at the air point, which has coordinates $(x, y, z)$ at time $\mathrm{t},{ }^{\circ} \mathrm{C}$.

The substation derivative, which is included in the previous equation (11), will be written as follows

$$
\frac{D T_{\text {air }}}{\partial t}=\frac{\partial T_{\text {air }}}{\partial t}+u \frac{\partial T_{\text {air }}}{\partial x}+v \frac{\partial T_{\text {air }}}{\partial y}+w \frac{\partial T_{\text {air }}}{\partial z} .
$$

The temperature field in an array of soils is described by the following equation of heat conductivity

$$
\frac{\partial T_{s}}{\partial t}=a_{s} \nabla^{2} T_{s},(x, y, z) \in M_{s} .
$$

Initial conditions

$$
\left\{\begin{array}{l}
T_{s}(x, y, z, 0)=T_{s 0}(z),(x, y, z) \in M_{s} \\
T_{\text {air }}(x, y, z, 0)=T_{\text {air } 0}(z),(x, y, z) \in M_{\text {air }}
\end{array}\right.
$$

Boundary conditions

$$
\left\{\begin{array}{l}
T_{a i r}(x, y, 0, t)=T_{1},(x, y) \in\left(x^{2}+y^{2} \leq D^{2} / 4\right) \\
T_{s}(x, y, 0, t)=f(t) \\
\left\{x^{2}+y^{2}>D^{2} / 4 \wedge(x-L)^{2}+y^{2}>D^{2} / 4\right\}
\end{array}\right.
$$

where $T_{s}(x, y, 0, t)$ - a function that determines the temperature on the surface of the soil and depends on the natural and climatic conditions [Shevchenko, 2017].

The condition of equality of the density of heat fluxes on the wall of the casing pipe

$$
\lambda_{2} \frac{\partial T_{2}}{\partial n}=-\alpha\left(T_{n}-T_{2}\right),(x, y, z) \in M_{2} \cap M_{n} .
$$

The differential equation of heat transfer establishes the connection between the coefficient of heat transfer on the surface of the casing and the temperature field of air

$$
\alpha=-\frac{\lambda_{\text {air }}}{T_{\text {air }}-T_{s}} \frac{\partial T_{\text {air }}}{\partial n} .
$$

The computational experiment was carried out using the ANSYS Fluent computational hydrodynamics package, which applies the method of spatial discretization to use the finite volume method with the calculation of unknown cells in the centers. To reduce the number of elements of the finite element mesh and to conserve computing resources, symmetry was used to indicate the condition of symmetry on a plane passing through the axis of a horizontal ground heat exchanger (Fig. 2). As a solver, we used a pressure solver: at the input $T_{\text {air }}(x, y, 0, t)$, a profile of velocity $v$ (velocity-inlet condition) was set up, at the output, a constant pressure $p=0$ (pressure-outlet condition) was assumed. For turbulence simulation, the Menter's model (k- $\omega$ Shear Stress Transport or SST model) [Menter, 1993] was used. The "Coupled" scheme was used to combine speed and pressure. The gradients of the variables in the cell-centers were determined by the Green-Gauss method on the nodes [Lyubimov, 2006]. The PRESTO! Method was used to interpolate pressure [Bruyaka, 2010]. An advection scheme of the second order was used to interpolate the convective windows. Also, the mesh conversion into polyhedral was applied. Afterwards, the mesh quality was improved with the repeated use of the TUI (Text User Interface) command / mesh / smooth "quality based".

\section{RESULTS}


The study of the dependence of energy extraction on the soil mass from the spatial orientation of the ground heat exchanger is presented in Table 1 and Figures 3, 4.

Table 1. Influence of the spatial orientation of the ground heat exchanger on its energy indices

\begin{tabular}{|c|c|c|c|c|c|c|}
\hline $\begin{array}{c}\text { Time of } \\
\text { operation } \\
t, c\end{array}$ & $\begin{array}{c}\text { Cooling the } \\
\text { air } \\
\Delta T,{ }^{\circ} \mathrm{C}\end{array}$ & $\begin{array}{c}\text { Loss of } \\
\text { pressure } \\
\Delta p, \text { Pas }\end{array}$ & $\begin{array}{l}\text { Thermal } \\
\text { power } \\
P_{m}, \mathrm{~W}\end{array}$ & $\begin{array}{c}\text { Pumping } \\
\text { capacity } \\
P_{n}, \mathrm{~W}\end{array}$ & $\begin{array}{c}\text { Effective } \\
\text { thermal power } \\
P_{e}, \mathrm{~W}\end{array}$ & $\begin{array}{c}\text { Effective thermal } \\
\text { energy during } \\
\text { operation } \\
E, \text { GJ }\end{array}$ \\
\hline \multicolumn{7}{|c|}{ Vertical heat exchanger } \\
\hline $10^{3}$ & 15,92 & 348 & 3383 & 105 & 3090 & 0,003 \\
\hline $10^{4}$ & 13,88 & 347 & 2950 & 104 & 2658 & 0,03 \\
\hline $10^{5}$ & 10,82 & 345 & 2300 & 104 & 2009 & 0,21 \\
\hline $10^{6}$ & 7,65 & 343 & 1626 & 103 & 1337 & 1,41 \\
\hline $10^{7}$ & 5,64 & 342 & 1199 & 103 & 910 & 9,60 \\
\hline \multicolumn{7}{|c|}{ Horizontal heat exchanger, $H=1 \mathrm{~m}$} \\
\hline $10^{3}$ & 4,55 & 3,2 & 967 & 1,0 & 964 & 0,001 \\
\hline $10^{4}$ & 4,06 & 3,2 & 863 & 1,0 & 860 & 0,009 \\
\hline $10^{5}$ & 3,41 & 3,2 & 725 & 1,0 & 722 & 0,074 \\
\hline $10^{6}$ & 3,09 & 3,2 & 657 & 1,0 & 654 & 0,662 \\
\hline $10^{7}$ & 2,92 & 3,2 & 621 & 1,0 & 618 & 6,22 \\
\hline \multicolumn{7}{|c|}{ Horizontal heat exchanger, $H=2 \mathrm{~m}$} \\
\hline $10^{3}$ & 7,15 & 3,4 & 1520 & 1,0 & 1517 & 0,002 \\
\hline $10^{4}$ & 6,4 & 3,4 & 1360 & 1,0 & 1357 & 0,014 \\
\hline $10^{5}$ & 5,35 & 3,4 & 1137 & 1,0 & 1134 & 0,116 \\
\hline $10^{6}$ & 4,13 & 3,4 & 878 & 1,0 & 875 & 0,903 \\
\hline $10^{7}$ & 3,56 & 3,4 & 757 & 1,0 & 754 & 7,69 \\
\hline \multicolumn{7}{|c|}{ Horizontal heat exchanger, $H=3 \mathrm{~m}$} \\
\hline $10^{3}$ & 9,03 & 3,8 & 1919 & 1,1 & 1916 & 0,002 \\
\hline $10^{4}$ & 8,11 & 3,7 & 1724 & 1,1 & 1720 & 0,017 \\
\hline $10^{5}$ & 6,81 & 3,7 & 1447 & 1,1 & 1444 & 0,147 \\
\hline $10^{6}$ & 5,2 & 3,7 & 1105 & 1,1 & 1102 & 1,14 \\
\hline $10^{7}$ & 4,06 & 3,7 & 863 & 1,1 & 860 & 8,88 \\
\hline
\end{tabular}

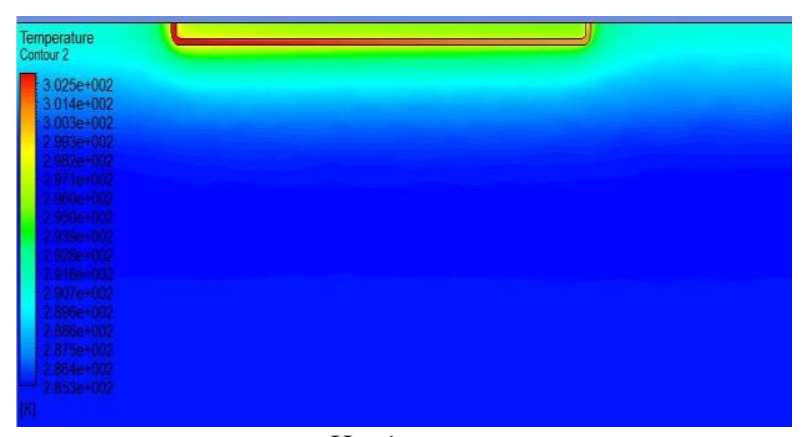

$H=1 \mathrm{~m}$

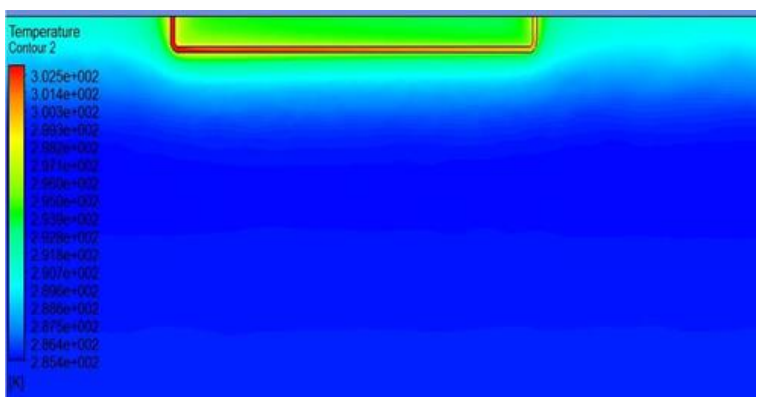

$H=2 \mathrm{~m}$

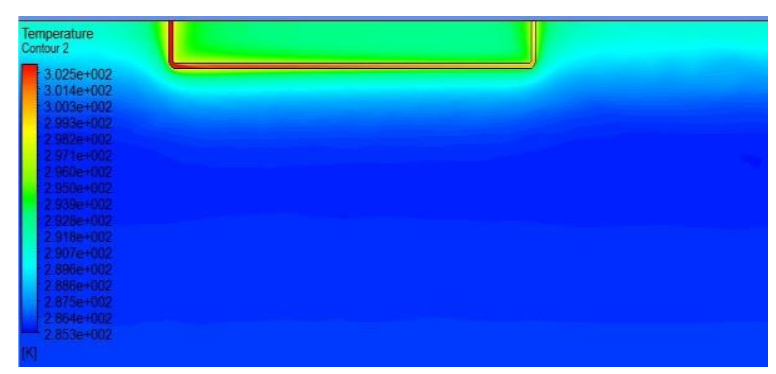




$$
H=3 \mathrm{~m}
$$

Figure 3. Temperature fields of cooled air and soil mass at different depths of the location of a horizontal ground heat exchanger

According to the results of the computational experiment (it was accepted: ambient air temperature $\mathrm{T} 1=30^{\circ} \mathrm{C}$; soil density $\mathrm{s}=1600 \mathrm{~kg} / \mathrm{m}^{3}$; thermophysical characteristics (coefficient of thermal conductivity) $\mathrm{s}=1,45 \mathrm{~W} /\left(\mathrm{m}^{3}{ }^{\circ} \mathrm{C}\right),(\mathrm{specific}$ heat capacity) $\mathrm{Cs}=1350 \mathrm{~J} /(\mathrm{kg} \mathrm{C}))$ to determine the influence of the spatial orientation of the soil heat exchanger on its energy performance Table 1 is constructed. It can be seen that the effective thermal energy during operation time comparing to a vertical ground heat exchanger decreases by $35 \%$ (for a horizontal heat exchanger with a depth of $1 \mathrm{~m}$ ), by $20 \%$ (for a horizontal heat exchanger with a depth of $2 \mathrm{~m}$ ), by $7.5 \%$ (for a horizontal heat exchanger with a depth of $3 \mathrm{~m}$ ).

For the longest time intervals of operation of the ground heat exchanger $\left(10^{7} \mathrm{~s}\right)$, the temperature fields of the cooled air and soil mass at different depths of the horizontal soil heat exchanger arrangement are shown (Fig. 3). According to the table, a graph of the effective thermal power versus the time of operation for different spatial orientation of the ground heat exchanger is constructed (Fig. 4). As can be seen from the figure, the vertical orientation of the ground heat exchanger is significantly more efficient, especially for the short time of operation of the ground heat exchanger and for the small depth of the horizontal heat exchanger arrangement. This is because the upper layer of the ground has greater seasonal variations in temperature (Fig. 3) and, as a consequence, a lower energy potential.

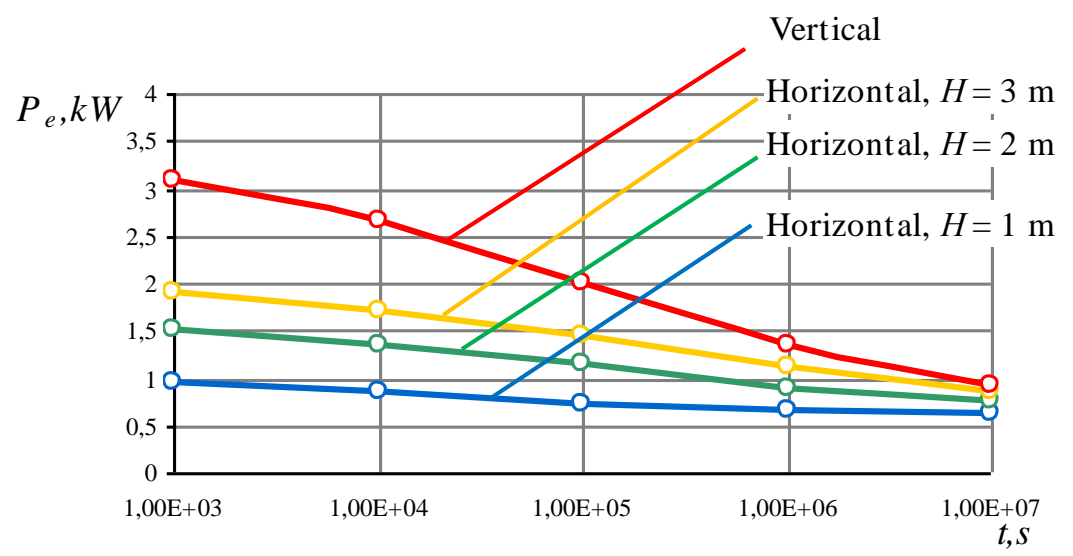

Figure 4. The dependence of the effective thermal power on the time of operation for the different spatial orientation of the ground heat exchanger

However, in the presence of sufficient land area near livestock premises, the lack of energy efficiency can be compensated by the length increase of a horizontal ground heat exchanger. The final variant of the location of a ground heat exchanger can be adopted after economic calculations for specific farm conditions.

\section{CONCLUSIONS}

A scientific and methodological base has been created to increase the efficiency of geothermal ventilation, which allows the use of thermal energy of the surface layers of the Earth to cool (heat) the incoming air. An actual scientific problem has been solved regarding the development of a mathematical model of the heat exchange process, which links the energy indicators of a horizontal ground heat exchanger with its parameters, as well as climatic conditions. The results of verification of this model are presented and the main energy indicators of the operation of a horizontal ground heat exchanger are calculated. An energy comparison has been made of a horizontal ground heat exchanger located at different depths with a vertical one. As a result of the work, the depth of the horizontal heat exchanger was established, for which the loss of thermal energy compared with the vertical is insignificant (less than 7.5\%). In addition, the operating time was determined, starting from which there are practically no differences in the level of thermal energy for all studied models $\left(>10^{7} \mathrm{~s}\right)$.

\section{REFERENCES}

1. Atam E., Helsen L. 2016. Ground-coupled Heat Pumps: Part 1 - Literature Review and Research Challenges in modeling and Optimal Control. Renewable and Sustainable Energy Reviews, Vol. 54, pp. $1653-1667$. https://doi.org/10.1016/j.rser.2015.10.007

2. Benli H. 2013. A Performance comparison between a Horizontal Source and Vertical Source Heat Pump System for a Greenhouse heating in the Mild Climate Elazig, Turkey. Applied Thermal Engineering, 1(50), $197-206$. https://doi.org/10.1016/j.applthermaleng.2012.06.005

3. Bruyaka V.A., Fokin V.G., Soldusova E.A., Glazunova N.A., Adeyanov I.E. 2010. Engineering Analysis at ANSYS Workbench. Samara: Ed. Samar. state tech. Univ., 271.

4. Bugayevsky V.M., Ostapenko O.M., Danil'chuk M.I. 2010. Influence of environment and technology of keeping on pig productivity. Scientific papers: Scientific and methodological journal. Ecology. Nikolaev, View of the ChSU them. Petra Mogili, Vol. 132(119), pp. 59-61. 
5. Cheilytko A.A., Ilin S.V., Nosov M.A. 2017. Creation of effective metallic thermal insulation constructions. Scientific Bulletin of National Mining University, Vol. 6(162), pp. 103-10.

6. Chiasson A.D. 2010. Modeling horizontal ground heat exchangers in geothermal heat pump systems. Proceedings of the 2010 COMSOL Multiphysics Conference, Boston, Massachusetts.

7. Ji Y., Qian H., Zheng X. 2017. Development and Validation of a Three-dimensional Numerical Model for predicting the Ground Temperature Distribution, Energy and Buildings, Vol. 140, pp. 261-267. https://doi.org/10.1016/j.enbuild.2017.01.079

8. Koviazin A.S. 2011. Development of a pig farm project for 12,000 fattening heads per year using alternative energy sources and energy-efficient process equipment: GDR report (final), DR 0111U004422, Institute of Livestock Mechanization of NAAS, Zaporizhzhia, p. 105.

9. Koviazin A.S., Velichko I.G. 2013. Influence of the material and casing wall thickness of a ground heat exchanger on energy extraction rate. Herald of national University "Lviv Polytechnic" "Power system. Engineering the environment. Automation", Vol. 758, pp. 57-62.

10. Koviazin A.S. 2017. The rationale for the thickness of the thermal insulation the inner tube of ground heat exchanger. Herald of aeroenginebuilding, Vol. 1, pp. 19-24.

11. Larwa B., Kupiec K., Komorowicz T., Gwadera M., Teper M. 2016. Modelling of heat transfer in ground heat exchangers. Technical transactions: Mechanics, 1-M/2016, pp. 141-150.

12. Lyubimov A.K. 2006. Application of the ANSYS system to solving problems of continuum mechanics. Practical Guide. Nizhny Novgorod. Publishing House of the Nizhny Novgorod State University, 227p.

13. Menter F.R. 1993. Zonal two equation k- $\omega$ turbulence models for aerodynamic flows. AIAA Paper 93-2906, 21 p. https://doi.org/10.2514/6.1993-2906

14. Mironov R.E., Shtern Yu.I., Shtern M.Yu., Rogachev M.S. 2016. A heat transfer model of a horizontal ground heat exchanger. AIP Conference Proceedings, 1727, 020015. https://doi.org/10.1063/1.4945970.

15. Sivasakthivel T., Murugesan K., Sahoo P.K. 2014. Optimization of Ground Heat Exchanger Parameters of Ground Source Heat Pump System for Space Heating Applications. Energy, Vol. 78, pp. 573-586. https://doi.org/10.1016/j.energy.2014.10.045

16. Shevchenko I., Kovyazin A., Kamiński J.R., Szeptycki A. 2017. Simulation of thermal field in soil. Problemy Inżynierii Rolniczej, Vol. 1(95), pp. 57-65.

17. Soni S.K., Pandey M., Bartaria V.N. 2015. Ground Coupled Heat Exchangers: A Review and Applications. Renewable and Sustainable Energy Reviews, Vol. 47, pp. 83-92. https://doi.org/10.1016/j.rser.2015.03.014

18. Wołoszyn J., Gołaś A. 2013. Modelling of a Borehole Heat Exchanger using a Finite Element with Multiple Degrees of Freedom. Geothermics, Vol. 47, pp. 13-26. https://doi.org/10.1016/j.geothermics.2013.01.002

19. Wołoszyn J., Gołaś A. 2016. Experimental Verification and Programming development of a new MDF Borehole Heat Exchanger Numerical Model. Geothermics, Vol. 59, Part A, pp. 67-76. https://doi.org/10.1016/j.geothermics.2015.10.006

20. Wołoszyn J., Gołaś A. 2017. Coefficient of Performance Stabilisation in Ground Source Heat Pump Systems. Journal of Sustainable Development of Energy, Water and Environment Systems, Vol. 5, Iss. 4, pp. $645-656$. http://dx.doi.org/10.13044/j.sdewes.d5.0173. 